\title{
Direito, Estado e Telecomunicações: névoa universal
}

Law, State and Telecommunications: Universal Fog

\section{Resumo}

O presente artigo figura como introdução à Revista de Direito, Estado $e$ Telecomunicações do Grupo de Estudos em Direito das Telecomunicações da Universidade de Brasília, descrevendo sinteticamente o conteúdo do presente número da revista. Em acréscimo, o texto ainda analisa os principais acontecimentos do setor no Brasil, bem como a normatização relativa ao ano de 2011, para registro das principais discussões político-jurídicas do setor de telecomunicações brasileiro referentes ao ano anterior ao da publicação.

\section{Abstract}

The article introduces this issue of the Law, State, and Telecommunications Review by way of presenting its contents. Statutes and the administrative regulation of 2011 pertaining to telecommunications are referred to in detail. It also addresses the main political and juridical discussions on the Brazilian telecommunications sector that took place the year before the publication of the journal's current volume.

\section{Apresentação}

O quarto volume da Revista de Direito, Estado e Telecomunicações segue a formatação original de abertura a artigos nacionais e estrangeiros referentes às telecomunicações em sentido amplo, mantendo-se a perspectiva de consolidação da revista como um instrumento de pesquisa jurídica setorial.

Para tanto, esta apresentação cumpre, para além da identificação das temáticas constantes da publicação, a função de registro histórico do arcabouço normativo setorial e do correspondente contexto socioeconômico e político das telecomunicações no Brasil. $\mathrm{O}$ artigo introdutório também registra as principais discussões jurídico-regulatórias que marcaram o ano de 2011.

Em seguida, o leitor se depara com o segundo tópico da revista, que corresponde a um artigo traduzido para a língua portuguesa de autoria de Walter Baer e Roy Ulrich intitulado "Votação online para iniciativas populares na Califórnia: coleta eletrônica de assinaturas". Nele se discute o processo de coleta eletrônica de assinaturas para proposições legislativas, 
tendo por ponto de partida o processo vigente para iniciativa popular na Califórnia, descrevendo-se como a assinatura online de petições de iniciativa popular funcionaria, como questões de segurança e outras objeções à coleta de assinaturas via internet poderiam ser abordadas e, finalmente, os prós e contras de se aplicar este método de coleta de assinaturas às iniciativas populares frente às suas consequências para o processo representativo democrático. Dentre as contribuições do artigo, vale ressaltar o diagnóstico de que a expansão do acesso à propositura de iniciativas populares via internet imporia, para preservação da seletividade das propostas, o rearranjo procedimental dos requisitos de iniciativa popular, mediante aumento do número mínimo de assinaturas ou, no extremo, a reinstituição do processo de iniciativa indireta então extinto no modelo de iniciativas populares da Califórnia. Mais do que isso, a constatação de que o sistema de iniciativas populares californianas resultou em um mecanismo de acesso elitizado ao canal de referendos populares é um dado relevante para a discussão aprofundada de propostas de abertura de canais participativos camufladas de sentido democrático, mas instituidoras de novos mecanismos demagógicos de desvio das finalidades públicas de deliberação legislativa.

O terceiro tópico da revista é dedicado à apresentação de estudos selecionados que abordem questões jurídicas relevantes do setor de telecomunicações brasileiro. No presente número, o artigo de Lucas Carvalho intitulado "Os meios de comunicação, a censura e a regulação de conteúdo no Brasil: aspectos jurídicos e distinções conceituais" aborda o árduo tema dos limites constitucionais do controle de conteúdo na radiodifusão, utilizando-se do antagonismo histórico entre a censura praticada no regime militar de 1964 a 1985 e a regulação de conteúdo, concluindo pela persistência da prática da censura mesmo após vinte anos de promulgação da Constituição de 1988. O diferencial, segundo o autor, da censura atual estaria não mais na atuação prioritária de estruturas estatais executivas, mas sim na chamada censura judiciária - uma prática institucional -, como também na censura social, enquanto procedimento de exclusão que incide sobre a produção e a difusão de discursos quando da prática do colaboracionismo e da autocensura. $\mathrm{O}$ artigo seguinte de Artur Coimbra intitulado "A Anatel como ferramenta republicana na internalização de normas internacionais" preocupa-se com uma das questões mais atuais do regime regulatório setorial aplicado às telecomunicações: a 
internalização de normas e pseudonormas internacionais no arcabouço regulamentar brasileiro. A abordagem trazida pelo autor, entretanto, não se restringe ao enunciado dos problemas de criação normativa via negociações em organismos e associações internacionais. Ele vai além ao ponderar a internalização de normas e pseudonormas internacionais no ordenamento jurídico brasileiro frente ao movimento histórico de deslocamento do centro de legitimação das políticas públicas setoriais do Poder Legislativo para o Poder Executivo, mediante o recurso ao arsenal conceitual neorepublicano de democracia contestatória, deliberativa e participativa. Glauciene Lara, por sua vez, em seu artigo intitulado "Liberdade de expressão versus direito à comunicação: a regulação da comunicação audiovisual na Argentina", analisa as fronteiras conceituais entre a liberdade de expressão, a liberdade de imprensa e o direito à comunicação, apoiando sua análise sobre a empiria do caso argentino de reforma legal da radiodifusão de 2009, no movimento de revisão do arcabouço normativo sobre concentração midiática daquele país. O último artigo da segunda parte da revista intitulado "Competência regulatória da Presidência da República no setor brasileiro de telecomunicações: política regulatória, republicanismo e interesse público", de Cássio Ribeiro, descreve, pautado por princípios republicanos, a atuação do Presidente da República, no Brasil, em sua função precípua de definição do regime jurídico de prestação de serviços de telecomunicações por intermédio do enfoque nos dois únicos momentos de exercício dessa competência, ou seja, a edição dos Planos Gerais de Outorgas de 1998 e 2008.

Para a quarta seção da revista, foi reservado espaço à transcrição de palestra proferida pelo vice-presidente mundial da Microsoft Corporation e primeiro responsável mundial pela área de assuntos jurídicos e corporativos, Brad Smith, na Faculdade de Direito da UnB, sob o título "Direito e Regulação na Internet: desafios jurídicos e oportunidades para o crescimento econômico", em que foram abordados diversos assuntos pertinentes à computação em nuvem [cloud computing], tais como: controle e armazenagem de informações sensíveis [control of sensitive information and storage]; jurisdição sobre o direito à privacidade [jurisdiction over privacy rights]; garantias de destruição de informações confidenciais [guarantees of destruction of confidential information]; direito contratual aplicado aos provedores de serviço de computação em nuvem [terms of agreement with 
cloud computing providers]; isenção tributária sobre serviços computacionais de nuvem [cloud computing as a specifically exempt or taxable service]. Em especial, Brad Smith discorreu sobre conflitos de lei no espaço referentes à privacidade e à segurança de dados hospedados em datacenters de escala mundial, bem assim sobre os interesses de bastidor presentes nos processos de fusões e aquisições envolvendo atores de peso no cenário da tecnologia da informação - Microsoft, Apple, Google, Motorola Molibty, Nortel - e sua relação com o direito de patentes.

A quinta seção da revista dedica-se ao registro do estágio em que se encontram temáticas atuais do setor de telecomunicações brasileiro traduzidas nos chamados informes setoriais. Para este número da Revista de Direito, Estado e Telecomunicações, foi selecionado um único informe setorial abrangente do cenário brasileiro de infraestrutura de redes para acesso à internet, contendo informações atualizadas sobre a regulação e a distribuição de redes de acesso e de transporte fixas e móveis, e redes de saída internacional, bem como sua relação com programas governamentais de inclusão digital, dentre eles: Telecentros.BR; GESAC; Banda Larga nas Escolas; Lei do Bem; e o Programa Nacional de Banda Larga (PNBL).

Finalmente, a última seção da revista se destina à reunião das normas primárias e secundárias do setor de telecomunicações publicadas no ano de 2011, organizadas por temas e referenciadas a tabelas informativas. No início dessa seção, consta a lista de abreviaturas e siglas do setor de telecomunicações mantida pelo GETEL/UnB, bem como, ao final, foi inserido um exaustivo índice alfabético e remissivo das normas primárias e secundárias do setor no ano de 2011. Cada tema presente em dita seção contém referências a normas de todos os níveis e a atos administrativos correlatos.

\section{O setor de telecomunicações no ano de 2011}

\section{Revisão quinquenal dos contratos de concessão de STFC}

Como era de se esperar, os primeiros meses de 2011 giraram em torno da meta de aprovação do Plano Geral de Metas de Universalização para o quinquenio 2011-2015 (PGMU III) na revisão quinquenal dos contratos de concessão. A aprovação do PGMU III, que foi postergada ao final de 2010 
pela Presidência da República até que se chegasse a um acordo entre Governo e concessionárias sobre seus pontos mais polêmicos, gravou a primeira metade do ano de 2011 com a indefinição sobre o destino dos deveres de universalização do Serviço Telefônico Fixo Comutado (STFC) e da infraestrutura essencial a sua prestação e de acesso à internet. A revisão quinquenal dos contratos de concessão do STFC serviu de palco para eleição de pontos controversos sobre o acompanhamento conjuntural regulatório da Anatel sobre o serviço concedido, em especial no que se refere aos itens em discussão quando da prorrogação de aprovação do PGMU III, ao final de 2010, quais sejam: a) custos e meios de financiamento das metas de universalização, que diferiam nas projeções da Anatel e de consultorias contratadas pelas empresas; b) metas de universalização em áreas rurais, em virtude do interesse de uso da faixa de $450 \mathrm{MHz}$ pela Telebras para expansão do acesso em banda larga a áreas remotas, ameaçando a expectativa das empresas de utilizarem a faixa de $450 \mathrm{MHz}$ para expandirem suas redes em áreas remotas; e c) conceituação do backhaul, em especial, a precisão da fronteira entre o que seria público - e reversível à União ao final dos contratos - e o que seria privado na rede.

A névoa que pairou sobre a dimensão de obrigações de universalização do regime público de telecomunicações evidenciou, por um lado, a crescente dificuldade governamental em definir diretrizes claras e em exercer seu poder extroverso de orientação unilateral sobre as cláusulas estatutárias dos contratos de concessão do STFC no que se refere à revisão de metas de universalização via revisão quinquenal dos contratos do STFC. Por outro lado, entretanto, a novidade gerada pela revisão quinquenal foi sentida pelo setor no esforço regulatório e governamental de demonstração de reavaliação conjuntural do andamento do STFC, tornando as opções de universalização mais difíceis, mas também mais ricas quando trouxe à tona as ponderações privadas de investimento e públicas de expansão e qualidade do serviço.

Pela primeira vez após sua reativação em meio à política pública de banda larga, a Telebras serviu de contrapeso em uma polêmica central do setor de telecomunicações ao provocar a exposição pública do interesse empresarial privado de operadoras de STFC sobre a faixa de $450 \mathrm{MHz}$, como ponto culminante da polêmica sobre seu uso, que fora inaugurada com a publicação da Consulta Pública $\mathrm{n}^{\circ}$ 24, de 12 de junho de 2009 e 
complementada pela edição de quatro resoluções do conselho diretor da Anatel, de números 555 a 558, de realinhamento de canalização e condições de uso de radiofrequência, todas publicadas no Diário Oficial da União de 24 de dezembro de 2010.

As antes restritas opções de atuação indireta do poder público na exploração de faixa de radiofrequências passaram a competir com previsões de custos de atuação direta do Estado via empresa estatal. Esclarecedores, a esse respeito, são os 42 cenários apresentados pela Anatel para uso da faixa de $450 \mathrm{MHz}$ com vistas à universalização na zona rural, que, no início de 2011, compôs o complexo jogo de negociações governo-empresas para edição do novo PGMU III.

As dificuldades experimentadas ao final de 2010 e que se estenderam por toda a primeira metade de 2011 para aprovação do PGMU III serviram como um teste à estabilidade do sistema regulatório de telecomunicações brasileiro e, em especial, sobre a previsão de revisões periódicas dos contratos de concessão. No âmbito do processo estendido de revisão quinquenal dos contratos de concessão de STFC, a discussão do novo PGMU contou com o pronunciamento da procuradoria jurídica especializada da AGU junto à Anatel pela legalidade da substituição de metas por compromissos de contrapartida via aditivos nos contratos de Serviços de Comunicação Multimídia, também opinando pela vedação da possibilidade de vinculação da venda de serviço de telefonia fixa à oferta de banda larga por considerá-la caso de venda casada.

No âmbito interno da Anatel, a iminência de aprovação do PGMU III voltou a atenção do Conselho Diretor para o esforço de aprovação de novas regras do Acesso Individual Classe Especial (AICE), e para reestruturação, pela área técnica, da proposta de Plano Geral de Metas de Qualidade (PGMQ) a ser anexada aos contratos de concessão revisados, com especial atenção à metodologia de apuração do cumprimento dos indicadores.

Na primeira semana de abril de 2011, o texto submetido pela relatora do PGMU III - a conselheira Emília Ribeiro - para apreciação pelo Conselho Diretor da Anatel revelava os pontos de negociação da proposta ligados à questão da reversibilidade do backhaul público. Um dos pontos nevrálgicos trazidos pela relatora consistiu na sua discordância do que se negociara entre a área técnica da Agência, o governo e as concessionárias, e que contara com parecer positivo da procuradoria jurídica especializada da Advocacia-

Revista de Direito, Estado e Telecomunicações, v. 4, n. 1, p. 1-30 (2012)

DOI: https://doi.org/10.26512/1str.v4i1.21573 
Geral da União (AGU) na Anatel: propunha-se a retirada da meta de ampliação do backhaul para substituí-la por um acordo negociado com as concessionárias, segundo o qual estas se comprometiam a ampliar a oferta de banda larga no atacado e no varejo. Para a relatora, tal proposta inviabilizaria o Programa Nacional de Banda Larga (PNBL) ao se abrir mão da ampliação do backhaul público.

Aqui, o embate se dá, no plano jurídico, de um lado, entre uma opção regulatória de preservação da política pública de expansão do backhaul como meio de garantia de um mercado competitivo via concentração do enfoque regulatório no atacado, e de outro lado, pela opção por uma administração conjuntural mais maleável e sensível aos interesses das concessionárias em reverter os seus investimentos de expansão da banda larga em patrimônio próprio não-reversível, coincidindo com o interesse governamental de curto prazo de célere ampliação do acesso à banda larga . Sob um ponto de vista estratégico, também em virtude da constatação recente de descontrole estatal sobre os bens reversíveis, como se verá mais adiante, cada uma das propostas tem o seu mérito e responde a princípios de eficiência administrativa.

Em outro ponto contrário aos resultados da negociação da área técnica da Anatel com as concessionárias, a relatora do PGMU III também se pronunciou contra a entrega da faixa de $450 \mathrm{MHz}$, de imediato, para as concessionárias, que estaria voltada, na negociação técnica, a facilitar o atendimento rural no novo plano de metas de universalização. Pelo contrário, ela propôs a edição, em 90 dias, de novo Plano de Metas de Universalização (PMU) específico para a expansão da oferta de serviços nas áreas rurais, conforme política pública definida em 2009, na Portaria n ${ }^{\circ} 431$, do Ministério das Comunicações. Embora não se tenha optado, ao final, por um plano de metas específico para a área rural, a faixa de $450 \mathrm{MHz}$ não foi entregue às concessionárias para cumprimento de suas metas, mas submetida à licitação em conjunto com a faixa de 2,5 GHz em 2012.

Praticamente nenhum assunto escapou das negociações para edição do novo PGMU para o quinquenio 2011-2015 (PGMU III), cabendo às operadoras fixas pressionarem pelo aumento da margem de tarifa de público mediante redução do Valor de Uso de Rede Móvel (VU-M) como valor de interconexão pago às operadoras móveis. A arbitragem do VU-M pago pela GVT à VIVO fora confirmada em sede judicial pelo Superior Tribunal de 
Justiça $^{1}$, fixando o mesmo VU-M para pagamento pela GVT à TIM mediante extensão judicial da decisão administrativa da Anatel no caso GVT vs. VIVO com base no princípio da deferência técnico-administrativa. Em outra frente, a Oi ingressou, em 2011, no CADE, bem como com pedido de arbitragem da Anatel para diminuição do VU-M, juntando-se ao esforço histórico da GVT nesse sentido.

Em 13 de abril de 2011, foi lançada consulta pública pela Anatel para novo adiamento de assinatura dos contratos revisados de concessão da telefonia fixa da inicial previsão de 2 de maio de 2011 para 30 de junho de 2011, visando desafogar o prazo de negociação do novo PGMU III, como parte da revisão quinquenal dos contratos de concessão.

Finalmente, em 2 de junho de 2011, o Conselho Diretor da Anatel aprovou a proposta do novo PGMU (PGMU III), que detinha inicial previsão regulamentar de edição por decreto presidencial até 31 de dezembro de 2010. Nela, recomendou-se ao Ministério das Comunicações o encaminhamento de um PGMU que excluísse as metas de backhaul, instituísse metas de acesso rural apoiadas na atribuição da faixa de $450 \mathrm{MHz}$ a um serviço de acesso popular vinculado ao cadastro do Bolsa Família (Novo AICE), que contava com 13 milhões de famílias registradas contra 184 mil assinantes do AICE de então, bem como o compromisso das operadoras de oferta de banda larga de $600 \mathrm{kpbs}$ por $\mathrm{R} \$ 35,00$ mensais. A proposta foi acompanhada da divulgação de estudo encomendado pelo SindiTelebrasil, que afirmava, em síntese, ser inviável economicamente para a operadoras de telecomunicações a oferta de 1 Mbps por $\mathrm{R} \$ 35,00$ mensais de forma linear e sem limite de download, salientando que a regulamentação deveria ser mais flexível para permitir a comercialização de pacotes de serviços nos quais estivessem embutidos a oferta da banda larga.

Um capítulo à parte foi reservado para a definição das cláusulas dos termos de compromisso a serem firmados com as concessionárias na renegociação do PGMU III e implantação do Programa Nacional de Banda Larga. Ao final de junho de 2011, as concessionárias e a equipe responsável do Ministério das Comunicações discutiam pontos de discórdia surgidos com a divulgação do teor dos termos de compromisso propostos pelo Governo Federal em 24 de junho de 2011. A tendência de desconexão entre

${ }^{1}$ Vide Recurso Especial no 1.171.688/DF, julgado em $1^{\text {o }}$ de junho de 2010.

Revista de Direito, Estado e Telecomunicações, v. 4, n. 1, p. 1-30 (2012)

DOI: https://doi.org/10.26512/lstr.v4i1.21573 
as metas de backhaul antes negociadas com as operadoras de STFC e a substituição de obrigações de expansão de telefones de uso público (TUP) e postos de serviço de telecomunicações (PST) veio finalmente à tona, mediante declaração atribuída à empresa Telefônica de que as metas do backhaul teriam sido ilegais e, portanto, não poderiam ter sua infraestrutura submetida às regras do regime público de afetação de bens reversíveis. Até mesmo o compromisso das concessionárias firmado com o Governo Federal quando da prorrogação do prazo para revisão dos contratos de concessão foi utilizado como argumento para a defesa da tese de que a infraestrutura implantada quando da substituição de metas de universalização por infraestrutura de backhaul não implicaria na afetação de tal estrutura ao serviço público, como evidencia declaração jornalística da Telefônica: "Eram metas [do backhaul], do nosso ponto de vista, ilegais, tanto é que as operadoras foram coletivamente à Justiça. Quando tiramos as ações, não houve um reconhecimento de que o governo tinha razão" 2 .

O profético tom das associações de defesa do consumidor de que seriam perdidos os benefícios públicos da troca de metas de universalização do STFC por infraestrutura de backhaul de 2008 caminhou a passos largos no discurso empresarial de 2011, mediante a tentativa de se desvincular a decisão de troca das metas de universalização do STFC do acordo entre o governo federal e as operadoras de investimentos dela originários.

Outro ponto de discórdia entre governo e concessionárias girou em torno do acréscimo, por parte do governo, dos valores de interconexão na base de cálculo do ônus da concessão pago pelas concessionárias a cada dois anos como parcela de preço público do contrato administrativo pertinente. A concessionária $\mathrm{Oi}$, à época, já colecionava vitórias judicias de exclusão da interconexão do cálculo do ônus da concessão.

Assinados na primeira quinzena de julho de 2011, não constaram dos termos de compromisso cláusulas de garantia de reversibilidade do backhaul sob o argumento de que tais termos teriam tratado de ofertas de serviços e não propriamente da infraestrutura de suporte - as redes - e, portanto, dispensariam, na visão do Ministério das Comunicações, a disciplina da reversibilidade, já que esta ocorreria naturalmente se a infraestrutura

${ }^{2}$ Samuel Possebon. Empresas e governo divergem sobre termo de compromisso. Teletime News, 27 de junho de 2011. 
construída para tais serviços fosse de suporte ao STFC. Não foi dessa vez que se esclareceu a relação esotérica entre STFC e banda larga. Pelo contrário, a incerteza sobre a extensão da infraestrutura de backhaul afetada ao STFC tem gerado o efeito maléfico de desincentivo à construção de novas redes que possam ser taxadas de reversíveis ou mesmo esforços como o descrito por representante da Telefônica de imunizar a infraestrutura de backhaul do efeito da reversibilidade.

O encerramento das negociações para edição do PGMU III marcou o definitivo descasamento entre a política pública de universalização da banda larga e determinado serviço de telecomunicações ao se anunciar a assinatura de termos de compromisso por parte das concessionárias de STFC desprovidos de cláusulas que vinculassem a infraestrutura de banda larga ao STFC, abrindo-se espaço para que o Programa Nacional de Banda Larga (PNBL) possa ser implementado via redes móveis de SMP. Embora o descasamento não seja novidade - afinal de contas, a banda larga é prestada via serviço específico, o Serviço de Comunicação Multimídia (SCM) -, o formato de responsabilidade dos termos de compromisso marca a compreensão de que, de um lado, estão os serviços com seus arcabouços regulamentares e, de outro lado, está a política de universalização da banda larga, cujo meio de implementação pode se valer dos serviços existentes, independentemente da natureza jurídica do serviço que opera a infraestrutura de suporte à banda larga.

Mais e mais, serviços e infraestrutura, assim como sua natureza jurídica, se destacam na regulação do setor de telecomunicações brasileiro. A banda larga, por sua vez, continua no limbo jurídico entre uma política pública abrangente de serviços de infraestrutura pública e privada, um serviço público em que tudo que toca se transforma em bem reversível, e um bem público de suporte a serviços da mais variada espécie.

Mesmo imersa no descrito limbo jurídico, no âmbito do planejamento governamental para o setor, a política de ampliação da banda larga foi pleiteada no Plano Plurianual (PPA) 2012-2015 com a previsão de pouco mais de R $\$ 7$ bilhões para esse fim. Em 13 de abril, a Comissão de Ciência e Tecnologia, Comunicação e Informática da Câmara dos Deputados aprovou a instalação de uma subcomissão para acompanhamento do Programa Nacional de Banda Larga (PNBL). Durante o ano de 2011, o esforço da pasta do Ministério das Comunicações em relação ao PNBL foi no sentido Revista de Direito, Estado e Telecomunicações, v. 4, n. 1, p. 1-30 (2012)

DOI: https://doi.org/10.26512/lstr.v4i1.21573 
de convencimento das operadoras de telefonia para entrada no PNBL com compromissos de velocidade, preços e expansão de serviços de banda larga fixa e móvel, o que gerou anúncios de adesão ao PNBL por parte de operadoras fixas, mas também móveis, como a TIM e a Claro. O PNBL apresentou-se, em 2011, como um índice de medida do teor da política pública vigente. Em finais de maio, vazamento de informação à imprensa especializada de que o então secretário executivo do Ministério das Comunicações, Cezar Alvarez, deveria ser substituído por encaminhamento do Ministro das Comunicações, Paulo Bernardo, para assumir a direção da Telebras evidenciou o conflito de perspectivas entre uma abordagem do PNBL em que a Telebras teria função estratégica - a visão da equipe original de proposta do PNBL ainda no governo Lula - e a de implementação do PNBL via empresas privadas de telecomunicações - a visão propugnada pelo Ministro das Comunicações, Paulo Bernardo. A crise política foi rapidamente contornada mediante intervenção do Palácio do Planalto, mantendo-se Cezar Alvarez na função de Secretário Executivo do Minicom, mas dando continuidade à substituição do então presidente da Telebras, Rogério Santanna, e do Secretário de Telecomunicações do Ministério, Nelson Fujimoto.

Se, por um lado, o índice de medição do humor político sobre a expansão da banda larga permaneceu dúbio tanto no que se refere à natureza jurídica do serviço e de sua infraestrutura de suporte quanto do caminho governamental para sua implantação via consolidação de rede da Telebras eminentemente de atacado, mas com possibilidade de atuação no varejo, por outro lado, o indicador internacional de performance do Brasil no quesito banda larga continuou em franco declínio. Em 19 de outubro de 2011, a Conferência das Nações Unidas sobre Comércio e Desenvolvimento (UNCTAD) divulgou relatório, posicionando a banda larga móvel brasileira como a mais cara e lenta na comparação com uma cesta de países em desenvolvimento, em que o Brasil perdia para Quênia, Marrocos, Sri Lanka, Turquia, Vietnã, dentre outros.

Não somente a banda larga permaneceu no centro das atenções de definição jurídica. A nova administração do Ministério das Comunicações de 2011 também foi marcada pelo posicionamento de sua consultoria jurídica, retomando o entendimento historicamente defendido na Anatel, de 
que sua competência de fiscalização do espectro não deveria ser cindida entre serviços de telecomunicações stricto sensu e radiodifusão. ${ }^{3}$

A tensão regulamentar produto da segmentação jurídica dos regimes das telecomunicações em sentido estrito e da radiodifusão não se restringiu, todavia, à discussão sobre a competência fiscalizatória da Agência e do Ministério das Comunicações sobre as estações radiodifusoras, mas foi além com o recrudescimento do debate sobre a destinação da faixa de $700 \mathrm{MHz}$ o dividendo digital - prevista para ser liberada em 2016 quando do apagão analógico, mediante encerramento das transmissões analógicas da TV aberta. As associações das empresas de telecomunicações, de um lado, e as associações das radiodifusoras, de outro, digladiaram-se, na mídia, pelo convencimento público da destinação da faixa de $700 \mathrm{MHz}$ aos serviços móveis ou à radiodifusão. Estudo do $\mathrm{CPqD}$ patrocinado pelo SindiTelebrasil defendeu, por exemplo, em outubro de 2011, que a destinação da faixa de $700 \mathrm{MHz}$ para serviços móveis não ocasionaria prejuízo à TV digital terrestre aberta, à medida que, em $91 \%$ dos municípios brasileiros, dos 57 canais de TV disponíveis, somente oito eram, de fato, ocupados, bem como em apenas 2,6\% dos municípios haveria mais de 16 canais em operação, algo que justificaria até mesmo a imediata destinação da faixa de frequência, de forma progressiva, para os serviços móveis. A Associação Brasileira de Radiodifusores (ABRA), por sua vez, no mesmo mês de outubro, enviou carta ao Ministério das Comunicações, solicitando que este interviesse junto à Anatel para impedir a prática de cancelamento de canais vagos por parte da Agência, que, segundo os radiodifusores, estariam ocupados ou em fase de consulta junto ao Ministério das Comunicações, mediante acusação de que a prática de cancelamento de canais estaria demonstrando a intenção da Agência de limpar o espectro para sua destinação a outros serviços. A carta finalmente pedia ao Ministério das Comunicações a manutenção da destinação da faixa de $700 \mathrm{MHz}$ aos radiodifusores mesmo após o ano de 2016.

O tema foi retomado no evento de inauguração da agenda políticoregulatória de 2012 - o Seminário Políticas de (Tele)Comunicações -,

${ }^{3}$ Vide Parecer $n^{\circ} 0036$ - 1.16/2011/RZL/GAB/CONJUR-MC/AGU, de 25 de janeiro de 2011, da Consultoria Jurídica do Ministério das Comunicações.

Revista de Direito, Estado e Telecomunicações, v. 4, n. 1, p. 1-30 (2012)

DOI: https://doi.org/10.26512/lstr.v4i1.21573 
quando em fevereiro de 2012, Daniel Slaviero, atuando como representante da radiodifusora SBT, defendeu a progressiva extinção dos canais analógicos de forma regionalizada, antecipando a migração nas capitais que inauguraram o processo de digitalização para até mesmo antes de 2016, embora indicando que para a maioria dos casos o prazo de 2016 deveria ser prorrogado em mecanismo de desligamento progressivo das redes analógicas. ${ }^{4}$ A paulatina aproximação do ano da esperada devolução da faixa por parte das radiodifusoras integralmente migradas às faixas de TV digital em 2016 - o chamado apagão analógico ou switch off da TV analógica, ou mesmo, dividendo digital -, não passou sem ser relembrada da posição das radiodifusoras de que a faixa deveria ser mantida com a radiodifusão para fins de regionalização das geradoras de TV para viabilização do ingresso de geradoras de TV locais no sistema de TV aberta, bem como devido à importância social diferenciada da radiodifusão no Brasil. Não menos contundentes foram os argumentos de questionamento da necessidade das operadoras móveis por mais espectro, refutados por operadoras de telefonia móvel com o uso de dados de expansão da banda larga móvel e crescente adoção de smartphones e tablets e sua demanda por novas faixas de frequência.

Outras cobiçadas faixas de radiofrequências - a de $2,5 \mathrm{GHz}$ e a de 450 $\mathrm{MHz}$ - persistiram na pauta regulatória de 2011 com previsão de licitação efetiva para 2012. Após a aprovação da proposta de PGMU III pelo Conselho Diretor da Anatel em 2 de maio de 2011, em pronunciamento sobre a decisão, o Ministro das Comunicações, Paulo Bernardo, sugeriu que se vinculasse a licitação da faixa de $2,5 \mathrm{GHz}$ à de $450 \mathrm{MHz}$ para que se aumentasse o poder de negociação governamental e para que se atraíssem as empresas a se envolverem com o cumprimento das metas de atendimento rural. Na Comissão Interamericana de Telecomunicações (Citel), a posição política brasileira de utilização da faixa de $450 \mathrm{MHz}$ para o desenvolvimento da banda larga em áreas de baixa densidade populacional transformou-se em uma recomendação para que os países das Américas incluíssem em seus planos nacionais de banda larga a faixa de $450 \mathrm{MHz}$

${ }^{4}$ XI Seminário Políticas de (Tele)Comunicações + TICs. Painel "Os desafios de um modelo convergente". CCOM/Teletime/TiInside. Brasília, 14 de fevereiro de 2012. 
para universalização do acesso em áreas insuficientemente atendidas, mediante canalização de $7 \mathrm{MHz}+7 \mathrm{MHz}$ com preferencialmente uma prestadora por área, parâmetros mínimos de qualidade e obrigações de cobertura da zona rural, bem como implementação de programas de financiamento que viabilizassem o desenvolvimento de redes de terceira geração. Cada vez mais aflora a constatação de que o sucesso das metas de universalização depende da existência de moedas de troca regulatória e que a efetividade das políticas públicas depende do pensamento regulatório estratégico de conjunto sobre todas as diversas dimensões do setor regulado.

A novidade a respeito da universalização ficou com a previsão de expansão dos atendidos pela modalidade de Acesso Individual Classe Especial (AICE) do STFC criado no PGMU de 2003, via Decreto 4.769, de 27 de junho de 2003, destinado a assinantes de baixa renda, que, na dicção do PGMU III, aprovado pelo Decreto 7.512, de 30 de junho de 2011, deve ser estendido pela regulamentação da Anatel para os inscritos no Cadastro Único para Programas Sociais do Governo Federal, no lugar de limitar sua fruição, como ocorria até então, aos cadastrados no Programa Bolsa Família.

\section{Bens reversíveis nos contratos de concessão de STFC}

No primeiro semestre de 2011, o tema dos bens reversíveis das concessionárias de STFC voltou à tona muito em razão da crescente preocupação setorial sobre o processo de finalização das concessões de STFC em 2025, ressuscitando críticas das associações de consumidores contra políticas públicas governamentais de troca de metas de universalização de PST para construção de um backhaul para banda larga, cuja natureza foi discutida durante todo o ano de 2010, resultando no entendimento de que somente o backhaul produzido a partir das mudanças das metas de universalização teria o caráter de bem reversível. Em paralelo, a preocupação sobre o devido acompanhamento administrativo dos bens reversíveis das concessões de STFC definitivamente entrou na pauta setorial, provocada por atos de controle externo do Tribunal de Contas da União (TCU) e por vazamento de informações à imprensa de que o órgão regulador das telecomunicações não teria uma listagem segura para acompanhamento dos bens reversíveis das concessionárias de STFC, dependendo exclusivamente das informações fornecidas pelas 
concessionárias e, mesmo assim, de forma errática e restrita aos anos 2001 e seguintes, à medida que elas alegaram não terem mais os dados de inventário patrimonial de 1998 a 2000. Com o valor residual dos bens reversíveis das concessionárias estimado por elas mesmas em $\mathrm{R}$ \$ 20,919 bilhões, já aplicada a depreciação, o tema dos bens reversíveis promete manter-se na pauta setorial com efeitos periódicos nas revisões quinquenais dos contratos de concessão até ao menos o ano estimado de devolução em 2025 se o STFC até lá não for extinto por esvaziamento de seu conteúdo prestacional via desvio de sua utilidade para o SCM. Nesse cenário, em 23 de maio de 2011, a ProTeste ajuizou ação civil pública contra a Anatel e a União para que se apresentasse a listagem de bens reversíveis das concessionárias de STFC, motivada, dentre outros fatores históricos, pela Consulta Pública $n^{\circ} 52$, que previa a isenção de anuência prévia da Anatel para que as concessionárias se desfizessem de bens reversíveis de até $\mathrm{R} \$ 1,5$ milhão.

Por mais desanimadora que seja a constatação de descontrole dos bens reversíveis, ela carrega consigo um processo de internalização da função reguladora na Anatel, na medida em que, de 1997 a 2006, quando o Regulamento de Controle de Bens Reversíveis foi aprovado, a estrutura governamental de controle da prestação indireta de serviços de telecomunicações dava-se por intermédio da empresa estatal responsável pelo inventário dos seus bens e pelo procedimento de privatização de 1998 . Com a privatização, o período de quase 10 anos até a assunção, pela administração indireta da União da função de controle preciso do inventário, ao menos como ordem normativa para tanto, demonstra o tempo de maturação resultado de alterações estruturais na forma de controle de serviços públicos: a transição de uma administração concentrada na prestação direta de serviços pelo Estado para uma administração desconcentrada de prestação indireta de serviços por contratos administrativos. Esse acontecimento também revela a importância de uma estrutura técnica sofisticada e garantida pelo regime do serviço público para fazer transparecer a efetiva deficiência de controle dos bens reversíveis que, até então, somente tinham espaço, nas discussões do setor, pelas vozes das concessionárias, que demandavam maior afrouxamento do controle sobre suas opções comerciais, algo aliás, reverberado em pronunciamentos de autoridades públicas da área e na projeção de desburocratização dos 
procedimentos de venda de bens reversíveis por parte da agência reguladora via discursos de demonização do Estado. Não se quer dizer com isso que a procura por um sistema de controle coerente com a dinâmica do setor não seja válida, mas que os discursos políticos, regulatórios e privados até então vinham despidos da informação vazada à imprensa de descontrole efetivo dos bens reversíveis das concessionárias. A ação da ProTeste, entretanto, serviu para fixação de certos aspectos regulatórios, tais como: a afirmação, por parte da Anatel, em defesa, de que o fornecimento de informações sobre os bens reversíveis de cada concessionária somente poderia sê-lo para órgãos públicos de controle e em caráter sigiloso, pois diriam respeito a dados sensíveis das empresas e seus modelos de negócios; o pedido da ProTeste em ter acesso às listagens de bens reversíveis à época da privatização do Sistema Telebras e quando da renovação dos contratos de concessão de STFC em 2005, como um requisito essencial ao controle social dos serviços públicos.

\section{Concorrência, fusões e aquisições}

Em sequência ao anúncio da Embratel, no segundo semestre de 2010, da intenção de adquirir $100 \%$ das ações preferenciais da operadora de TV a Cabo Net Serviços, de que já era acionista, então controlada pela Globo, visando a incorporação total da Net pela Embratel e dependendo da aprovação do antigo PL 29/2007, da Câmara dos Deputados, convertido no PLC 116/2010, do Senado Federal, sobre revisão do marco regulatório da mídia por meios confinados, efetivamente aprovado na forma da Lei do Serviço de Acesso Condicionado (Lei 12.485/2011), a Embrapar e sua controlada Embratel alcançaram, em meados de janeiro de 2011, a participação no capital social total da Net de 91,86\%, após aquisição, através de oferta pública (OPA) de 21,81\% das ações preferenciais da Net Serviços. Em janeiro, a Embratel detinha 92,27\% das ações preferenciais da Net, que somados às ações preferenciais detidas pela Embrapar, chegavam a 97,63\% de tais ações na Net Serviços.

Em continuidade ao processo de consolidação da aquisição da Telemar pela Oi, em 13 de janeiro de 2011, em Assembleia Geral Extraordinária da Tele Norte Leste S.A., foi ratificada a aquisição da Invitel, holding da cadeia societária da Brasil Telecom. Em 26 de janeiro, por sua vez, foram definidos 
os detalhes para ingresso da Portugal Telecom no capital da Telemar Norte Leste (controle do Grupo Oi), mediante desembolso, pelos portugueses, de $\mathrm{R} \$ 8,32$ bilhões, dando-lhes a participação direta e indireta de 22,38\% na Telemar Norte Leste. Como resultado da transação, os fundos de pensão passaram a ter sua participação societária diluída de 49,9\% para $37,7 \%$.

Em outra frente de promoção da diversidade de atores no setor, foi anunciada, em fevereiro de 2011, a primeira parceria concreta de operadora de rede virtual móvel (MVNO) em acordo da TIM com a Porto Seguro Telecomunicações, por intermédio da Datora Telecomunicações, para otimização de custos de telefonia celular de clientes e corretores de seguros da Porto Seguro, ficando sob sua responsabilidade a operação, gestão de tráfego, emissão de contas e atendimento a clientes e acordos de interconexão.

Finalmente, quanto ao processo de aquisição da operadora móvel Vivo, em 24 de março de 2011, o Conselho Diretor da ANATEL aprovou, por unanimidade, a reestruturação do Grupo Telefônica, como última etapa do processo de compra da totalidade do controle acionário da Vivo, após a saída da Portugal Telecom. Houve, todavia, divisão no posicionamento dos votos dos conselheiros da ANATEL no que se refere às contrapartidas à aprovação da reestruturação, expressos em compromissos de cobertura e expansão da rede pertinentes, dentre outros, à instalação de acessos adicionais em ADSL até 31 de dezembro de 2012, à expansão da rede com tecnologia Fiber to the Home (FTTH) até 31 de dezembro de 2012, à consolidação de Centro de Inovação Tecnológica até 31 de dezembro de 2011, à implantação de rede móvel 3G em 150 novos municípios até 31 de dezembro de 2012, ao provimento de conexão móvel 3G, manutenção técnica e Provedor de Serviço de Conexão à Internet (PSCI) para 100 escolas rurais até 31 de dezembro de 2012. Isso não se deu, todavia, sem críticas do setor de que algumas das contrapartidas ofertadas pela Telefônica já teriam sido implementadas antes do compromisso em si.

A onda de fusões e aquisições experimentada nos anos anteriores entre operadoras fixas e móveis chegou ao seu exaurimento em 2011, quando o cenário de grupos econômicos detentores de operações fixas e móveis apaziguou os ânimos por alterações regulamentares que resolvessem a dubiedade jurídica do STFC frente à banda larga, eliminando-se o interesse empresarial em esclarecimento normativo, haja vista a solução efetiva da 
abertura dos mercados fixo, móvel e de banda larga via agregação das atividades sob o mesmo grupo econômico.

No que toca ao mercado de TV por assinatura, pela primeira vez, no Brasil, a base de assinantes da TV por satélite ultrapassou a de TV a Cabo. Em abril de 2011, o mercado de TV por assinatura alcançou 10,657 milhões de assinantes, dos quais 49,2\% correspondiam a assinantes de DTH (5,243 milhões) e 48,1\% a assinantes de TV a Cabo (5,126 milhões).

\section{Cenário internacional}

$\mathrm{O}$ direito do usuário de conectar qualquer tipo de dispositivo à rede IP, algo antecipado pela petição da Skype à $\mathrm{FCC}^{5}$, foi regulamentado, em 2011, no Chile. A Lei 20.453, de 26 de agosto de 2010, alterou a Ley General de Telecomunicaciones (Lei 18.168, de 2 de outubro de 1982) e consagrou o princípio de neutralidade de rede para os usuários e consumidores de internet. Em 2011, ela foi regulamentada com regras dirigidas aos provedores para garantia de preservação da qualidade dos serviços prestados, dentre elas, as regras de vedação de interferência ou bloqueio do direito dos usuários de utilizarem ou oferecerem conteúdos e serviços, bem como vedação da priorização de conteúdos, mediante proibição de que a qualidade do serviço seja afetada por medidas de gestão de tráfego de dados, a garantia do direito do usuário de conectar qualquer tipo de dispositivo à rede IP e o dever dos provedores de entrega, de forma fidedigna, de todos os serviços oferecidos.

No cenário mundial, o ano de 2011 marcou o rearranjo de mercado dos dispositivos representativos da concentração de utilidades tecnológicas comunicacionais com a liderança da Apple no mercado mundial de smartphones, praticamente dobrando suas vendas de 2010 para 2011, enquanto a Samsung caminhou rapidamente para a terceira posição mundial em volume comercializado com crescimento de mais de $190 \%$ em relação ao ano de 2010 e a Nokia perdeu a primeira colocação em um mercado em

${ }^{5}$ LIBERTELLI, Christopher; GOLDBERG, Henry; KUMAR, Devendra T. Petição para confirmação do direito do consumidor de utilização de programa de comunicações pela internet em redes sem fio e de conexão de dispositivos em tais redes. In: RDET 3(1): 43-74, 2011.

Revista de Direito, Estado e Telecomunicações, v. 4, n. 1, p. 1-30 (2012)

DOI: https://doi.org/10.26512/lstr.v4i1.21573 
que HTC e LG também avançaram respectivamente $106 \%$ e $250 \%$ em relação a seu desempenho do ano de 2010. Para um mercado que comercializara cerca de 288 milhões de aparelhos, a marca de 462 milhões demonstrou a consolidação da tendência de expansão dos smartphones como bens essenciais de comunicação dessa década traduzida na frase de efeito "celular é produto essencial" de campanha do Instituto Brasileiro de Defesa do Consumidor (Idec) de setembro de 2011.

Em paralelo, as smart TVs e locadoras virtuais passaram a ocupar a linha de frente de utilidades atrativas, cujo ponto culminante se deu em setembro de 2011, com o ingresso da Netflix no Brasil, embora sem presença local, restringindo-se a serviços de cobrança e suporte ao consumidor.

Aos tablets foi aberta a política pública governamental de facilitação de sua expansão no mercado nacional brasileiro mediante desoneração tributária do pagamento de PIS e COFINS, bem como mediante um conjunto de causas judiciais inauguradas, em abril de 2011, na Califórnia e subsequentemente expandidas para a Europa, Austrália e Ásia, referentes a acusações, por parte da Apple, de que a Samsung estaria ferindo patentes relacionadas ao design do iPad por aparelhos das linhas Galaxy e Ace da Samsung, bem como de alegações da Samsung de quebra de suas patentes por parte da Apple, evidenciando como tais aparelhos, suas tecnologias e utilidades têm ocupado, paulatinamente, o centro do palco do setor mundial de comunicação, bem assim, a valorização empresarial da estrutura judicial de certos países para a solução de litígios sobre tecnologias da informação e comunicação.

No lugar do termo guerra de patentes comumente utilizado nas análises de propriedade intelectual da indústria de dispositivos móveis, o termo trolls das patentes passou a designar as empresas que se dedicam a ameaçar os pequenos desenvolvedores de aplicativos e jogos para os sistemas operacionais móveis com a cobrança judicial de royalties decorrentes e.g. do simples uso do kit de desenvolvimento de aplicativos fornecido pelas próprias detentoras de sistemas operacionais Android, iOS, Symbian ou RIM/Blackberry.

No que diz respeito ao uso dos chamados espaços vagos (white spaces) na faixa de $700 \mathrm{MHz}$, a Ofcom, na Inglaterra, tomou, no segundo semestre de 2011, decisão histórica de abertura da faixa para uso livre mediante cadastro público. 


\section{Convergência de licenças de serviços}

O ano de 2011 também presenciou a retomada de um movimento antigo de simplificação do sistema de licenças de serviços da Anatel primeiramente implementado com a criação do Serviço de Comunicação Multimídia.

A nova proposta de regulamento do Serviço Limitado Privado, que passou o ano de 2011 em tramitação, previa a unificação de 14 licenças sob a batuta do Serviço Limitado Privado, quais sejam: 1) Serviço Limitado Privado, em todas as suas submodalidades; 2) Serviço Limitado Especializado, de interesse restrito, em todas as suas submodalidades; 3) Serviço de Rádio Táxi Especializado; 4) Serviço Limitado de Fibras Óticas; 5) Serviço Limitado de Estações com Operação Itinerante; 6) Serviço Limitado de Radioestrada; 7) Serviço Especial de Supervisão e Controle; 8) Serviço Especial de Radioautocine; 9) Serviço Especial de Radiorrecado; 10) Serviço Especial de Radiochamada; 11) Serviço Limitado Móvel Privativo; 12) Serviço Avançado de Mensagens; 13) Serviço Especial de Rádio Acesso; 14) Serviço Telefônico Público Móvel Rodoviário (Telestrada).

\section{Comunicação audiovisual de acesso condicionado}

O PLC 116/2010 inaugurou o ano de 2011 esmaecido e cercado de dúvidas quanto ao seu futuro. Os primeiros meses do ano trouxeram dúvidas quanto à continuidade do esforço concentrado governamental em sua aprovação. A migração da responsabilidade temática sobre o andamento do Programa Nacional de Banda Larga do Gabinete Civil para o Ministério das Comunicações contribuiu para afastar a dimensão diferencial que o setor de comunicações ocupava, como um todo, na agenda presidencial.

Embora o interesse de atores como a Embratel no ingresso no mercado de TV a Cabo fosse um propulsor do projeto de lei de comunicação de massa (PL 29/2007, da Câmara dos Deputados, convertido no PLC 116/2010, do Senado Federal), outros atores e interesses permaneceram em firme oposição à redação do projeto. Até mesmo uma iniciativa das operadoras Oi, Telefônica e Brasil Telecom, então reputada por analistas do setor como economicamente inviável, para compra e distribuição dos direitos do Campeonato Brasileiro de Futebol, teve o potencial de criar 
embaraços ao trâmite do projeto, cuja redação separava distribuição e produção de conteúdo de mídia.

No âmbito dos esforços da agência reguladora de retomada do processo de outorgas de TV a Cabo, mediante adoção do preço administrativo básico de emissão da autorização, então em 9 mil reais, para incremento da competição no setor, representação interposta pelo Ministério Público junto ao Tribunal de Contas da União, provocado por denúncias do Sindicato Nacional das Empresas Operadoras de Sistemas de Televisão por Assinatura (SETA), defendeu a tese de que as normas editadas pela Anatel de reforma do planejamento de TV a Cabo desrespeitaria a Lei do Cabo (Lei 8.977/95), considerando que o custo administrativo pela expedição do serviço deveria ser substituído por um método de cálculo que realmente representasse o valor da licença outorgada, sob pena de "potenciais perdas de receita para o Erário".

Após mais de quatro anos e meio de tramitação no Congresso Nacional, o PLC 116/2010, originariamente PL 29/2007, foi aprovado no Senado Federal, disciplinando os serviços de TV por assinatura sob a nova nomenclatura de Serviço de Acesso Condicionado (SeAC), injetando 2,6 vezes mais recursos para o audiovisual brasileiro do que existia até então, mediante a instituição da Contribuição para o Desenvolvimento do Cinema (Condecine), destinada ao Fundo Setorial do Audiovisual, com transferência potencial estimada de $\mathrm{R} \$ 660$ milhões das empresas de telecomunicações para o setor audiovisual. ${ }^{6}$

Dentre as questões jurídicas prováveis de serem levantadas no Supremo Tribunal Federal, encontra-se o questionamento da constitucionalidade de atribuição de funções à Ancine por projeto de lei de iniciativa do Poder Legislativo. A Lei 12.485 , de 12 de setembro de 2011, foi sancionada com dois vetos: o veto ao $\S 4^{\circ}$, do art. 11 , que atribuía às programadoras a definição dos critérios e formas de divulgação da classificação indicativa, mantendo-se incólume a regulamentação em vigor do Ministério da Justiça sobre o tema; e o veto ao inciso III do art. 33, que previa a possibilidade de cobrança de tarifa de ligação local para o Serviço de Atendimento ao

${ }^{6}$ OLIVEIRA, João Maria de; RIBEIRO, Carolina Teixeira. TV por assinatura e regulação: desafio à competitividade e ao estímulo à produção local. In: Radar-IPEA 15: 19-27, 2011. 
Consumidor (SAC) por telefone, bem como previa a restrição da obrigação de atendimento pessoal aos consumidores durante o horário comercial, preservando-se, portanto, a disciplina mais benéfica ao consumidor então prevista no Decreto 6.523 , de 31 de julho de 2008, de gratuidade das ligações ao SAC e permanente disponibilidade do serviço.

A Lei 12.485, de 12 de setembro de 2011 (Lei do SeAC), introduziu modificações normativas relevantes para o setor de telecomunicações lato sensu, atingindo indiretamente a radiodifusão. $\mathrm{O}$ seu art. $1^{\circ}$, parágrafo único, exclui do seu campo de aplicação os serviços de radiodifusão sonora e de sons e imagens, ressalvados os dispositivos que expressamente façam menção a esses serviços ou a suas prestadoras. Em outra frente de abertura do mercado de TV por assinatura às concessionárias de STFC, o seu art. 37, $\S 18$ prevê que a concessionária de STFC poderá solicitar, a qualquer tempo, a adequação do contrato de concessão para eliminação das restrições que vedem a possibilidade de que a concessionária do serviço e suas coligadas, controladas ou controladoras prestem serviço de TV a Cabo, inclusive nas áreas geográficas de prestação do serviço objeto da concessão. Tal possibilidade de concessionárias de STFC explorarem mais de um serviço de telecomunicações decorreu da nova redação do art. 86 da Lei Geral de Telecomunicações introduzida pela Lei 12.485/2011, que alterou o art. 86 da LGT para autorizar as concesssionárias de serviços de telecomunicações a prestarem diretamente outros serviços sob o mesmo CNPJ, gerando, em certas situações, diminuição do ônus tributário. Um exemplo disso se revela na eliminação do pagamento de valor de uso de rede móvel (VU-M) pago pela operadora fixa para a móvel de um mesmo grupo econômico por se tratar, até então, de pessoas distintas, o mesmo ocorrendo para os pagamentos de TU-RL de operadoras móveis a fixas do mesmo grupo econômico. Como as operadoras fixas já haviam conseguido, à época, unificar a prestação de STFC e SCM sob o mesmo CNPJ, a alteração do art. 86, embora proteja esta prestação unificada, não operará efeitos concretos no ônus tributário correspondente. Como se pode notar, para efeitos mercadológicos e tributários, a banda larga prestada sobre a infraestrutura de STFC é percebida como um serviço imbricado ao de telefonia, exceto para sua efetiva classificação como serviço público.

A aprovação da Lei do SeAC, entretanto, não foi recebida por todos com aplausos. A Sky, por exemplo, emitiu comunicado alegando a Revista de Direito, Estado e Telecomunicações, v. 4, n. 1, p. 1-30 (2012) 
inconstitucionalidade da política de cotas de conteúdo nacional por ofensa ao princípio de liberdade de manifestação do pensamento e de imprensa, bem como a alteração do art. 86 da LGT como alteração legal de benefício específico voltada à solução concreta de duas operações de interesse de atores relevantes do setor: a venda da participação da Globo na NET para a Embratel; e a consolidação entre TVA e Telefônica.

$\mathrm{O}$ ano se encerra com abertura da Consulta Pública da Anatel $n^{\circ}$ 65, de 19 de dezembro de 2011, sobre a proposta de Regulamento do Serviço de Acesso Condicionado (SeAC) e das regras disciplinadoras da prestação dos serviços por ele englobados: o Serviço de TV a Cabo, o Serviço de Distribuição de Sinais Multiponto Multicanal (MMDS), o Serviço de Distribuição de Sinais de Televisão e de Áudio por Assinatura via Satélite (DTH) e o Serviço Especial de TV por Assinatura (TVA).

\section{Infraestrutura essencial de banda larga e a Telebras}

Em 20 de janeiro de 2011, a Telebras obteve uma licença de Serviço de Comunicação Multimídia (SCM), o que abriu a possibilidade de prestação de serviço de conexão banda larga diretamente ao consumidor final. Até então, as licenças detidas pela empresa já a autorizavam a ofertar capacidade de rede no atacado. A efetiva atuação no varejo, entretanto, depende da definição de critérios de atuação pelo Comitê Gestor de Políticas de Inclusão Digital (CGPID), que foi integrado ao Ministério das Comunicações no Governo Dilma Rousseff.

A implementação da infraestrutura de redes da estatal e sua funcionalidade de oferta de links para conexão à internet, entretanto, ainda dependia, em janeiro de 2011, de negociações para se firmarem os contratos de cessão de fibras óticas das estatais de energia elétrica - Furnas, Chesf, Eletrobrás, Eletronorte - e Petrobrás.

O significado da Telebras não somente como um mero braço empresarial do Estado, ou mesmo uma solução para o problema de universalização/massificação da banda larga, foi esclarecido pelo novo Ministro das Comunicações, Paulo Bernardo, em janeiro de 2011 ao comentar que a Telebras "entrou para ser mais um concorrente, competidor, para ajudar a regular o mercado e baixar o preço". Sob tal perspectiva, a Telebras integra a visão estratégica de governo como componente da função 
reguladora, uma referência de excelência de serviço e infraestrutura, um referencial setorial de preços e um agente de competição.

Um tema de referência constante nos debates e pronunciamentos sobre o PNBL e o papel da Telebras em sua implementação foi o incômodo em se falar em banda larga em velocidades de $512 \mathrm{kbps}$, produto da necessária justificação política da banda larga como um projeto que não onerasse em demasiado o erário. Como se costumou dizer no setor, uma banda larga bem estreita, com o efeito perverso de não se tomar o tema da revolução informacional como um projeto de nação.

Com relação ao papel da estatal nas negociações de edição de um novo Plano Geral de Metas de Universalização, que acompanha a revisão quinquenal dos contratos de concessão de STFC adiados, inicialmente, de 31 de dezembro de 2010 para 2 de maio de 2011, no mês de março, a Telebras, pela primeira vez, pronunciou-se oficialmente em ofício do seu presidente interino - Antônio Carlos Alff - encaminhado à Anatel, formalizando o seu interesse na faixa de $450 \mathrm{MHz}$ para a "promoção da inclusão digital em áreas remotas, rurais e de baixa densidade populacional". Com o avanço das negociações entre o Ministério das Comunicações, a Anatel e as concessionários ocorridas nos primeiros meses de 2011, tal certeza de utilização da faixa pela Telebras foi substituída pelo entendimento da área técnica da Anatel de que a liberação do uso da faixa de $450 \mathrm{MHz}$ para as concessionárias seria parte das medidas necessárias para assegurarem o cumprimento das metas de universalização do novo PGMU III nas áreas rurais. No ofício de formalização do interesse da Telebras em utilizar a faixa de $450 \mathrm{MHz}$, deixou-se claro que, nos termos do art. 13 da Resolução $\mathrm{n}^{\circ}$ 558, de $2010^{7}$, a autorização à Telebras para uso dos blocos da faixa de $450 \mathrm{MHz}$ não impediria o cumprimento das metas de universalização das concessionárias de STFC, à medida que à Telebras

${ }^{7}$ Resolução Anatel $\mathrm{n}^{\circ}$ 558, de 20 de dezembro de 2010 (Aprova o Regulamento sobre Canalização e Condições de Uso de Radiofrequências nas Faixas de $450 \mathrm{MHz}$ a $470 \mathrm{MHz}$ ): "Art. 13. A prestadora do serviço que esteja autorizada a fazer uso das radiofreqüências objeto deste regulamento deverá, se solicitada, fornecer infraestrutura às prestadoras que estejam obrigadas a atender às metas de acesso, conforme Plano de Metas para Universalização (PMU) e Plano Geral de Metas para Universalização (PGMU), a preços razoáveis, em condições adequadas."

Revista de Direito, Estado e Telecomunicações, v. 4, n. 1, p. 1-30 (2012)

DOI: https://doi.org/10.26512/lstr.v4i1.21573 
caberia "fornecer (...) infraestrutura às prestadoras que [estivessem] obrigadas a atender às metas de acesso". A isso se seguiu pronunciamento do Secretário-Executivo do Ministério das Comunicações, César Alvarez, de que, na verdade, a Telebras não teria pedido a faixa para ela e sim solicitado que a faixa fosse utilizada para políticas públicas.

Frustrada a iniciativa de uso da faixa de $450 \mathrm{MHz}$ no âmbito do PNBL e ausente mecanismo expresso na Lei de Licitações que dispenssasse a Telebras de licitações no provimento de serviços ao Governo, ela se concentrou na função de atacado de provimento de redes.

Em fevereiro de 2011, a Telebras firmou contratos de cessão de uso das fibras ópticas instaladas nas linhas de transmissão de energia elétrica de Furnas, Chesf, Eletrosul e Eletronorte, que foram homologados pela Aneel em ato publicado no DOU de 25 de maio de 2011. O primeiro trecho do backbone para atendimento ao PNBL foi então previsto para a interligação entre Brasília e Itumbiara (Goiás), utilizando-se das fibras ópticas instaladas nas redes de transmissão de Furnas.

O ciclo de preparação da infraestrutura foi coroado com o primeiro contrato de oferta de capacidade de transmissão de dados no atacado para empresas privadas, quando em início de junho de 2011 a Telebras assinou contrato para oferta de link com capacidade de 100 Mbps a um custo inferior a $\mathrm{R} \$ 200,00$ o Mb por mês com a empresa Sadnet, que atende a região de Santo Antônio do Descoberto, em Goiás, sob o compromisso de oferta de um pacote de conexão de $1 \mathrm{Mbps}$ a $\mathrm{R} \$ 35,00$ por mês com garantia de $20 \%$ da velocidade ofertada. Em meio a outros contratos firmados a partir daí na rota entre Brasília e Itumbiara, o presidente da estatal expressamente enunciou o objetivo da empresa: o de regular o preço no atacado.

\section{Aferição de qualidade do provimento de acesso à internet em redes fixas e móveis}

A aprovação dos Regulamentos de Gestão da Qualidade do Serviço de Comunicação Multimídia (RGQ-SCM) e do Serviço Móvel Pessoal (RGQSMP) sofreu intensas críticas por parte das concessionárias de STFC e operadoras de SMP, sob o fundamento de que se estaria ferindo o princípio da livre iniciativa em razão das exigências acenadas nas correspondentes consultas públicas, dentre elas a fixação de percentual mínimo de suas redes 
para a venda ao atacado, a obrigatoriedade de instalação de PTTs em cada área de registro de atuação de grupo com poder de mercado significativo (PMS), a criação de Entidade Aferidora da Qualidade para aplicação e registro dos indicadores de rede definidos na regulamentação de qualidade de redes para encaminhamento de ofertas de acesso às redes de grupos com PMS. A crítica empresarial concentrou-se no argumento de que tais metas somente poderiam ser dirigidas ao próprio Estado e que seriam indicativas para a iniciativa privada, propondo-se, assim, a extensão do princípio constitucional do art. 174 para além das atividades econômicas stricto sensu. $\mathrm{O}$ argumento foi além, entretanto, do discurso de fusão de horizontes público e privado quando passou a identificar como fins prioritários da regulamentação de qualidade a universalização do serviço, atribuindo à proposta o vício de desvio de finalidade.

A voz uníssona das empresas de telecomunicações sobre o advento de metas de qualidade da banda larga foi de que o Brasil estaria inovando onde nenhum outro país atuou ao optar por metas regulamentares ao invés da exigência de transparência.

\section{Processo decisório da Anatel: sigilo e transparência}

Voltou à pauta da agência reguladora uma questão que permeou seu funcionamento desde sua criação: a confidencialidade das reuniões do conselho diretor da Anatel e dos autos de processos administrativos. Em 14 de março de 2011, o Ministério Público Federal do Distrito Federal encaminhou recomendação ao Conselho Diretor da Anatel para revisão do procedimento de aplicação de caráter sigiloso aos PADOs, por considerar que a Agência transformara a medida excepcional de sigilo em regra nos processos administrativos que são públicos, exigindo-se da autoridade competente a demonstração de qual das hipóteses legais do art. 39 da LGT justificariam a confidencialidade. Além disso, a recomendação comparou as reuniões do conselho diretor da ANATEL com julgamentos de tribunais superiores, que devem ser públicos, sugerindo a imediata abertura ao público das reuniões e sessões em respeito ao princípio constitucional da publicidade.

Não somente em resposta à provocação do Ministério Público, no segundo semestre de 2011 o Conselho Diretor da Anatel aprovou a Portaria 
$n^{\circ}$ 941, de 28 de outubro de 2011, em plena transição para nova presidência, que dispôs sobre o acesso pelo público em geral aos documentos e informações acostados em Procedimento Administrativo para Apuração de Descumprimento de Obrigações (Pado), revertendo a prática institucional de sigilo como princípio. Em menos de vinte dias após sua publicação, foi publicada a Lei 12.527 , de 18 de novembro de 2011, que prevê, como regra, a publicidade dos atos processuais administrativos, sem condicionamentos. O tratamento mais avançado de transparência dos atos de poder da Administração Pública previsto na Lei 12.527/2011 impôs para 2012 revisões pontuais na disciplina regulamentar da Anatel sobre o tema.

\section{Marco Civil da Internet e crimes cibernéticos}

O setor também viu, em 2011, o desenrolar de antiga trama sobre a normatização do conteúdo, crimes cibernéticos, propriedade intelectual e responsabilidades na internet. Ainda em maio 2009, o parlamento europeu foi obrigado a se posicionar sobre proposta do presidente francês, Nicolas Sarkozy, de controle governamental de downloads na internet. Em 6 de maio de 2009, o parlamento europeu aprovou uma emenda à lei de telecomunicações proibindo qualquer iniciativa contra a livre circulação de arquivos na internet, mesmo após o presidente francês ter fechado acordo com a comissária de telecomunicações e os ministros de telecomunicações do bloco em sentido contrário. O parlamento reverteu o encaminhamento da casa para aceitar uma emenda do Partido Verde, definindo que, nos países pertencentes à Comunidade Europeia, apenas uma ordem judicial poderia restringir o acesso à internet. Mesmo assim, o parlamento francês aprovou proposta em que se cria um órgão administrativo para desligamento de usuário da internet por má conduta.

No Brasil, o assunto do controle da internet não só tomou forma na discussão da tramitação dos projetos de lei da Câmara dos Deputados e do Senado Federal - Projetos números 29 e 182, respectivamente -, que propunham a inserção de restrições à disponibilização de vídeos pela internet, mas também no projeto do Senador Eduardo Azeredo, aprovado no Senado em julho de 2008, e em tramitação na Câmara em 2009, que criava treze novos crimes com penas que variavam de um a três anos de prisão. $\mathrm{O}$ Ministério da Justiça ingressou no debate chamando a si a responsabilidade 
de formulação do marco civil da internet, mediante edição de consulta pública com ênfase no tema da privacidade e liberdade de expressão na internet sob o codinome de projeto de construção colaborativa do marco civil da internet e com o objetivo de fornecer uma meta convergente das políticas públicas governamentais referentes à internet. $\mathrm{O}$ marco regulatório permaneceu disponível para contribuições ao final de 2009 com projeção de submissão à consulta pública do texto final do projeto de lei que deveria ser encaminhado ao Congresso Nacional em 2010.

A discussao sobre a aplicação do art. 222 da Constituição Federal aos portais de internet foi retomada durante o décimo Seminário Política de (Tele)Comunicações, em Brasília, com o choque de entendimento da aplicação dos limites lá estabelecidos sobre portais de internet. Paulo Castro, diretor geral do portal Terra, argumentando que a aplicação do dispositivo constitucional estaria limitada à radiodifusão e à imprensa, enquanto Evandro Guimarães, diretor da Abert e vice-presidente de relações institucionais da TV Globo, entendia que o artigo se aplicaria a qualquer empresa jornalística, fosse qual fosse o meio de transmissão.

Finalmente, a Casa Civil da Presidência da República, em agosto de 2011, encaminhou o projeto de Marco Civil da Internet em meio à difícil tramitação do PL 84/99, de iniciativa do Senador Eduardo Azeredo (PMDB/MG), então apelidado por seus críticos de AI-5 digital, tendo-se em vista a percepção de que a tipificação de crimes cometidos via internet do PL 84/99 endureceria demasiadamente a ingerência estatal em um meio comunicacional de natureza aberta. A expectativa com o ingresso do projeto de Marco Civil da Internet é que ele absorva as discussões até então travadas em torno ao PL 84/99 ou ajude na reconformação deste projeto de criminalização de condutas via internet, exugando-os, para que somente enunciem crimes já não tratados em outras searas e levem em conta a intenção do agente infrator, reservando-se ao Marco Civil a função de normatização do modelo de retenção de dados na internet.

\section{TV e rádio digital}

Enquanto, por um lado, representantes de radiodifusoras defendiam o modelo de aplicação incondicional da disciplina da comunicação social a todos os meios de transmissão, por outro lado, agora de política industrial e 
de interesse nacional, o ano de 2011 esboçou melhor o cenário de fraquezas quanto à política pública de incentivo à tecnologia nacional.

$\mathrm{O}$ ano não começou bem para a política de expansão do padrão nipobrasileiro de TV digital, quando, em janeiro de 2011, o Instituto Nacional das Comunicações de Moçambique (INCM) anunciou a adoção do padrão europeu de TV digital terrestre (DVB-T2), seguindo a orientação da Comunidade de Países da África Austral (Sadc). O mesmo caminho foi seguido pela África do Sul, em janeiro de 2011.

$\mathrm{O}$ embate sobre o destino do dividendo digital da faixa de $700 \mathrm{MHz}$ continuou sendo regularmente resgatado durante o ano com manifestações de operadoras móveis e de radiodifusoras, de um lado propalando a essencialidade da faixa para preservação e ampliação da banda larga móvel no Brasil e, de outro lado, a importância da cultura nacional e regional, bem como a demanda por alternativas de TV digital aberta fora dos centros urbanos. A novidade, em 2011, resultou de declaração sobre o futuro da televisão (FoBTV - Future of Broadcast Television), da reunião da Cúpula Mundial de Televisão, em Shangai, na China, em que se propôs a uniformização tecnológica da TV digital em âmbito mundial dos modelos ATSC, ISDB-TV e DVB-T para que não se reproduzisse, na TV digital, a mesma fragmentação tecnológica do padrão analógico expresso nos padrãos PAL, NTSC e SECAM.

A posição brasileira na Citel quanto à recomendação de atribuição da faixa de $700 \mathrm{MHz}$ para serviços móveis no padrão norte-americano, revista em 2011 para possibilitar também a utilização do padrão Ásia-Pacífico, permaneceu a de aguardar a transição completa da TV digital, em 2016, para pronunciar-se sobre o tema.

Em processo de ajuste de arestas, a fase crítica de definições políticas da TV digital foi ultrapassada em 2011 tanto pela necessária espera pelo que se delineará no ano de 2016, quando da previsão de extinção da transmissão analógica, quanto pela ascensão de um novo astro digital: o rádio. A rádio digital avançou em sua formulação de destinação da faixa de VHF de 76 MHz e $88 \mathrm{MHz}$ para a operação da rádio AM em padrão digital na extensão da faixa FM. Dita faixa de frequência deve ser liberada em 2016 dos canais 5 e 6 da TV analógica em sua migração para a TV digital. A demanda pela utilização dos canais 5 e 6 para a rádio digital foi verbalizada ao Governo em diversos eventos durante o ano de 2011 pela Abert, a Câmara de Rádio e 
os presidentes de entidades estaduais de radiodifusão. Ao contrário da TV digital, o debate da rádio digital promete ser mais célere, cingindo-se à opção governamental por uma das duas tecnologias HD Radio ou DRM, a definição sobre a faixa de frequência para a migração e o destino da rádio AM.

\section{Conclusão}

Os princípios regulatórios de produção normativa concentrada na agência representativa do setor, de disciplina de infraestrutura como bem essencial e necessário à competição, de enfoque sobre a utilidade do serviço, mediante proteção do consumidor e fixação de parâmetros de qualidade dos serviços e de planejamento convergente foram aprofundados em 2011, no setor de telecomunicações brasileiro, à exceção da assimetria regulatória, que persiste nebulosa mesmo frente à implementação do Programa Nacional de Banda Larga e à revisão quinquenal dos contratos de concessão de STFC, com a consequente atualização do Plano Geral de Metas de Universalização em sua terceira encarnação (PGMU III).

O ano de 2011 marcou o início do contra-ataque das concessionárias, capitaneadas pela $\mathrm{Oi}$, à política de assimetria regulatória entre a prestação do STFC em regime público e privado, clamando não pela extinção das obrigações de universalização incidentes sobre a prestação em regime público, mas pela extensão de tais obrigações às autorizadas de STFC.

Em outra frente, o pedido interposto pela Oi perante a Anatel, em 30 de novembro de 2011, para anulação de diversos dispositivos - arts. $8^{\circ}, 10,11$, 13, 14, 15, 16, 17, 18, 19, 20, 21, 22 e 23 - do Regulamento sobre Gestão da Qualidade do Serviço Móvel Pessoal (RGQ-SMP), aprovado pela Resolução $\mathrm{n}^{\circ} 575$, de 28 de outubro de 2011, por alegada violação aos princípios da legalidade, proporcionalidade e finalidade, demonstra o perfil de varejo das discussões que despontam para 2012 em um cenário de valorização da qualidade dos serviços prestados em regime privado, como estrofe em preparação do ocaso épico do STFC.

O Conselho Editorial 